\title{
Recapitulation of Candidate Systemic Lupus Erythematosus-Associated Variants in Koreans
}

\author{
Ki-Sung Kwon ${ }^{1,2}$, Hye-Young Cho ${ }^{1,2}$, Yeun-Jun Chung ${ }^{1,2 *}$ \\ ${ }^{1}$ Department of Microbiology, College of Medicine, The Catholic University of Korea, Seoul 06591, Korea, ${ }^{2}$ Integrated Research \\ Center for Genome Polymorphism, College of Medicine, The Catholic University of Korea, Seoul 06591, Korea
}

\begin{abstract}
Systemic lupus erythematosus (SLE) is a chronic autoimmune disease that affects multiple organ systems. Although the etiology of SLE remains unclear, it is widely accepted that genetic factors could be involved in its pathogenesis. A number of genome-wide association studies (GWASs) have identified novel single-nucleotide polymorphisms (SNPs) associated with the risk of SLE in diverse populations. However, not all the SNP candidates identified from non-Asian populations have been validated in Koreans. In this study, we aimed to replicate the SNPs that were recently discovered in the GWAS; these SNPs have not been validated in Koreans or have only been replicated in Koreans with an insufficient sample size to conclude any association. For this, we selected five SNPs (rs1801274 in FCGR2A and rs2286672 in PLD2, rs887369 in CXorf21, rs9782955 in LYST, and rs3794060 in NADSYN1). Through the replication study with 656 cases and 622 controls, rs 1801274 in FCGR2A was found to be significantly associated with SLE in Koreans (odds ratio, 1.26, 95\% confidence interval, 1.06 to $1.50 ; p=$ 0.01 in allelic model). This association was also significant in two other models (dominant and recessive). The other four SNPs did not show a significant association. Our data support that FCGR polymorphisms play important roles in the susceptibility to SLE in diverse populations, including Koreans.
\end{abstract}

Keywords: FCGR2A, genomewide association studies, single-nucleotide polymorphism, systemic lupus erythematosus

\section{Introduction}

Systemic lupus erythematosus (SLE) is a chronic heterogeneous systemic autoimmune disease that can, in principle, affect any kind of body organ or cell, primarily in young women [1]. In SLE, altered immune responses may stimulate the production of autoantibodies and immune complex deposits in body organs, resulting in organ damage [2]. Like other autoimmune diseases, SLE has a complex pathogenesis, and the disease mechanism is still unclear; however, it is widely accepted that genetic factors could be important contributors to SLE [2, 3]. Accordingly, several lines of evidence have supported that SLE may be explained by genetic factors. For instance, the concordance rate of SLE in monozygotic twins ( $24 \%$ to $58 \%$ ) is higher than the rate in dizygotic twins ( $2 \%$ to $5 \%$ ), and also, the disease heritability is high (>66\%) [4-6].

A number of genome-wide association studies (GWASs) have identified novel single-nucleotide polymorphisms (SNPs) associated with the risk of SLE, such as HLA, PTPN22, STAT4, IRF5, TNFAIP3, BLK, and BANK1, in various ethnic groups, but most of the GWASs have been performed in Caucasians [1, 7-13]. In Korea, most of the previously reported SNPs were validated by GWASs, and potentially East Asian-specific SNPs, such as the SNPs in ETS1, IKZF1, and SLC15A4, were also identified [14-16]. Recently, Bentham et al. [12] performed a large-scale GWAS with 7,219 cases and 15,991 controls in Europeans and defined 43 SLE loci, including 10 new loci.

Among the SLE-associated loci in Bentham et al. [12], some of them have not been replicated in the Korean population, and others were replicated but not concluded to be associated due to a limited sample size. In this study, we aimed to replicate five SNPs that were not replicated or concluded to be association in Koreans. 


\section{Methods}

\section{Study subjects}

All participants were of Korean ancestry. For the replication study, 656 SLE patients (males, 11; females, 645; age $[$ mean $\pm \mathrm{SD}$ ], $33.7 \pm 12.1$ years) were recruited from the Rheumatology Center at Seoul St. Mary's Hospital, The Catholic University of Korea, South Korea. All patients had been diagnosed as having SLE according to the American College of Rheumatology-revised criteria for SLE $[17,18]$. In addition, the allele frequencies for healthy Korean population as control were derived from the Korea Reference Genome Database $(n=622)$. This study was performed under the approval of our institutional review board (MC12TIMI0026).

\section{SNP genotyping}

In this study, we selected five SNPs (rs1801274 in FCGR2A locus, rs2286672 in PLD2 locus, rs887369 in CXorf21 locus, rs9782955 in LYST, and rs3794060 in NADSYN1) that were identified to be associated with SLE from a previous GWAS [12] but have not been tested in a Korean population. Five SNPs were genotyped using the TaqMan SNP Genotyping Assay (Applied Biosystems, Foster City, CA, USA) for allelic discrimination. TaqMan polymerase chain reaction (PCR) and fluorescence measurements were performed using a ViiA 7 Real-Time PCR System (Applied Biosystems) using a 384-well plate according to the manufacturer's instructions.

\section{Statistical analysis}

Chi-square test was used to estimate Hardy-Weinberg equilibrium with the genotype data of the SLE cases and controls. Significant differences in alleles and genotype frequencies between cases and controls were assessed using SPSS version 22 (IBM Corp., Armonk, NY, USA). Odds ratios (ORs) were calculated by case and control allele frequencies with $95 \%$ confidence intervals (CIs). The p-values $<0.05$ were regarded as statistically significant.

\section{Results}

\section{Candidate SNP selection}

Of the 43 SLE-associated loci identified by Bentham et al. [12], we narrowed down the candidate SNPs for this study per the following criteria: SNPs that had not been replicated in the Korean population, SNPs with a minor allele frequency above $5 \%$ in an East Asian population, and SNPs that were replicated in the Korean population but inconclusive owing to the limited sample size. Seven of the 43 SNPs were not replicated in the Korean population, and five of them showed a minor allele frequency above $5 \%$ in the East Asian population (Supplementary Table 1). Therefore, we selected the five SNPs for a replication study in Koreans (rs1801274 in FCGR2A locus, rs2286672 in PLD2 locus, rs887369 in CXorf21 locus, rs9782955 in LYST, and rs3794060 in NADSYN1) (Table 1). Three of them were nonsynonymous,

Table 1. SNP information for allele genotyping

\begin{tabular}{llllc}
\multicolumn{1}{c}{ SNPs } & Gene locus & \multicolumn{1}{c}{ Location } & \multicolumn{1}{c}{ SNP effect } & Amino acid change \\
\hline rs1801274 & FCGR2A & Chr.1:161479745 & Missense variant & H131R \\
rs2286672 & PLD2 & Chr.17:4712617 & Missense variant & R172C \\
rs887369 & CXorf21 & Chr.X:30577846 & Synonymous variant & V209V \\
rs9782955 & LYST & Chr.1:236039877 & Intron & - \\
rs3794060 & NADSYN1 & Chr.11:71187679 & Intron & - \\
\hline
\end{tabular}

$\mathrm{SNP}$, single-nucleotide polymorphism.

Table 2. Alternative allele frequencies of five SNPs in patients with SLE and controls

\begin{tabular}{|c|c|c|c|c|c|c|c|c|c|}
\hline \multirow{2}{*}{ SNPs } & \multirow{2}{*}{ Ref./Alt. } & \multirow{2}{*}{ Case } & \multirow{2}{*}{ Control } & \multicolumn{6}{|c|}{1000 Genome Database } \\
\hline & & & & All & AFR & AMR & EAS & EUR & SAS \\
\hline rs1801274 & $\mathrm{A} / \mathrm{G}$ & 0.285 & 0.24 & 0.44 & 0.53 & 0.45 & 0.28 & 0.51 & 0.42 \\
\hline rs2286672 & $\mathrm{C} / \mathrm{T}$ & 0.382 & 0.38 & 0.19 & 0.01 & 0.1 & 0.42 & 0.09 & 0.39 \\
\hline rs887369 & $\mathrm{A} / \mathrm{C}$ & 0.968 & 0.979 & 0.9 & 0.92 & 0.92 & 0.94 & 0.76 & 0.95 \\
\hline rs9782955 & $\mathrm{T} / \mathrm{C}$ & 0.89 & 0.88 & 0.84 & 0.98 & 0.75 & 0.88 & 0.77 & 0.76 \\
\hline rs3794060 & $\mathrm{C} / \mathrm{T}$ & 0.38 & 0.38 & 0.35 & 0.14 & 0.45 & 0.38 & 0.7 & 0.15 \\
\hline
\end{tabular}

SNP, single-nucleotide polymorphism; SLE, systemic lupus erythematosus; Ref./Alt., reference allele/alternative allele; All, average of entire population; AFR, African; AMR, American; EAS, East Asian; EUR, European; SAS, South Asian. 
Table 3. Genotypic association between each SNP and SLE risk in Korean SLE patients and healthy controls

\begin{tabular}{|c|c|c|c|c|c|c|}
\hline \multirow{2}{*}{\multicolumn{2}{|c|}{ Variable }} & \multicolumn{5}{|c|}{ SNP ID (gene) } \\
\hline & & $\begin{array}{l}\text { rs1801274 } \\
(\text { FCGR2A) }\end{array}$ & $\begin{array}{l}\text { rs2286672 } \\
(P L D 2)\end{array}$ & $\begin{array}{l}\text { rs887369 } \\
\text { (CXorf2 1) }\end{array}$ & $\begin{array}{l}\text { rs9782955 } \\
\quad(\angle Y S T)\end{array}$ & $\begin{array}{c}\text { rs3794060 } \\
\text { (NADSYNI) }\end{array}$ \\
\hline Ref./Alt. & & $\mathrm{A} / \mathrm{G}$ & $\mathrm{C} / \mathrm{T}$ & $\mathrm{A} / \mathrm{C}$ & $\mathrm{T} / \mathrm{C}$ & $\mathrm{C} / \mathrm{T}$ \\
\hline $\mathrm{AF}$ & & 0.285 & 0.382 & 0.968 & 0.89 & 0.38 \\
\hline SLE cases & $\begin{array}{l}\mathrm{RH} / \mathrm{HT} / \mathrm{AH} \\
\text { Total }\end{array}$ & $\begin{array}{c}339 / 260 / 57 \\
656\end{array}$ & $\begin{array}{c}155 / 188 / 60 \\
403\end{array}$ & $\begin{array}{c}13 / 0 / 393 \\
406\end{array}$ & $\begin{array}{c}12 / 117 / 525 \\
654\end{array}$ & $\begin{array}{c}258 / 298 / 100 \\
656\end{array}$ \\
\hline Controls & $\begin{array}{l}\mathrm{RH} / \mathrm{HT} / \mathrm{AH} \\
\text { Total }\end{array}$ & $\begin{array}{c}359 / 227 / 36 \\
622\end{array}$ & $\begin{array}{c}239 / 293 / 90 \\
622\end{array}$ & $\begin{array}{c}1 / 24 / 597 \\
622\end{array}$ & $\begin{array}{c}9 / 130 / 483 \\
622\end{array}$ & $\begin{array}{c}241 / 292 / 89 \\
622\end{array}$ \\
\hline Allelic model & $\begin{array}{l}\text { OR }(95 \% \mathrm{Cl}) \\
\text { p-value }\end{array}$ & $\begin{array}{c}1.26\left(1.06^{-1.50)}\right. \\
0.01\end{array}$ & $\begin{array}{c}1.00(0.84-1.21) \\
0.93\end{array}$ & $\begin{array}{c}0.65(0.37-1.12) \\
0.12\end{array}$ & $\begin{array}{c}1.12\left(0.88^{-1.43)}\right. \\
0.37\end{array}$ & $\begin{array}{c}1.01(0.86-1.18) \\
0.93\end{array}$ \\
\hline Dominant model & $\begin{array}{l}\text { OR }(95 \% \mathrm{Cl}) \\
\text { p-value }\end{array}$ & $\begin{array}{cl}1.28 & (1.02-1.59) \\
& 0.03\end{array}$ & $\begin{array}{c}1.00(0.77-1.29) \\
0.99\end{array}$ & $\begin{array}{c}0.05(0.01-0.37) \\
0.00\end{array}$ & $\begin{array}{cl}0.79 & (0.33-1.88) \\
& 0.59\end{array}$ & $\begin{array}{c}0.98\left(0.78^{-1.22)}\right. \\
0.83\end{array}$ \\
\hline Recessive model & $\begin{array}{l}\text { OR }(95 \% \mathrm{Cl}) \\
\text { p-value }\end{array}$ & $\begin{array}{cl}1.55 & (1.01-2.39) \\
& 0.046\end{array}$ & $\begin{array}{cl}1.03 & (0.73-1.47) \\
& 0.85\end{array}$ & $\begin{aligned} 1.27 & (0.64-2.50) \\
& 0.50\end{aligned}$ & $\begin{array}{c}1.17(0.89-1.53) \\
0.25\end{array}$ & $\begin{array}{c}1.08(0.79-1.47) \\
0.64\end{array}$ \\
\hline
\end{tabular}

$\mathrm{SNP}$, single-nucleotide polymorphism; SLE, systemic lupus erythematosus; Ref./Alt., reference allele/alternative allele; $\mathrm{AF}$, alternative allele frequency; $\mathrm{RH}$, number of homozygous references; $\mathrm{HT}$, number of heterozygous; $\mathrm{AH}$, number of homozygous alternates; OR, odds ratio; $\mathrm{Cl}$, confidence interval.

and the other two were intronic SNPs.

\section{Association with SLE}

A total of 656 cases and 622 controls were enrolled and genotyped to analyze the association with SLE. Minor allele frequencies of the five SNPs in this study were similar to those in East Asians from 1000 Genomes Database (Table 2) [19], suggesting that this study group can represent the Korean population and that our genotyping was reliable. We performed an association analysis with three different genetic models: allelic, dominant, and recessive (Table 3).

Of the five SNPs, rs1801274 in FCGR2A was significantly associated with the risk of SLE in all three models, but the other four SNPs did not show a significant association. Under allelic model, the minor allele frequency of genotype $\mathrm{G}$ in rs1801274 was significantly higher in SLE patients (AF = $0.285)$ than in controls $(\mathrm{AF}=0.24)(\mathrm{OR}, 1.26 ; 95 \% \mathrm{CI}, 1.06$ to $1.50 ; \mathrm{p}=0.01)$. Also, the dominant model of minor allele in rs 1801274 seems significantly associated with SLE (OR, 1.28; $95 \% \mathrm{CI}, 1.02$ to 1.59 ; $\mathrm{p}=0.03$ ). Under recessive model, the genotype $\mathrm{G} / \mathrm{G}$ of $\mathrm{rs} 1801274$ was significantly associated with SLE (OR, 1.55; 95\% CI, 1.01 to 2.39 ; $\mathrm{p}=0.046$ ).

\section{Discussion}

SLE is a complex autoimmune disease caused by complex interactions between genetic and environmental components $[4,20]$. Its high heritability and relatively higher risks in siblings suggest a genetic contribution to the risk of SLE [21, 22]. In this study, we aimed to replicate five SNPs that were discovered in Caucasians [12] but not replicated in Koreans (rs2286672 in PLD2 locus, rs887369 in CXorf21 locus, rs9782955 in LYST, and rs3794060 in NADSYN1) or replicated in Koreans (rs1801274 in FCGR2A locus) with insufficient sample size to conclude any association. Through a replication study with 656 cases and 622 controls, rs1801274 in FCGR2A was found to be significantly associated with SLE in Koreans. However, the other four candidate SNPs were not replicated in Koreans.

The risk allele (G) of rs1801274 in FCGR2A is a missense variant that changes a histidine to arginine [23]. The human FC $\gamma$ receptor (FCGR) gene family (FCGR2A, FCGR2B, and FCGR2C) is located on chromosome 1q23, and it is considered to be associated with the susceptibility to SLE $[23,24]$. Functionally, human Fc $\gamma$ receptor is involved in anti-inflammatory regulation of immune responses. Another important role of human Fc $\gamma$ receptor is the clearance of immune complexes [25]. Indeed, FCGR polymorphisms have been reported to be associated with the susceptibility to autoimmune diseases, including SLE [26-28]. A well-known polymorphism is the missense variant at amino acid 131 in FCGR2A, which decreases binding affinity to human immunoglobulin $G[23,28,29]$. The homozygosity for R131, being regarded as the low-binding allele of FCGR2A, is known to be associated with a 1.30-fold greater risk for the development of SLE compared with both of the other genotypes combined $[30,31]$. Thus, FCGR2A-R131 may have potential roles in causing defective immune complex clearance and increased tissue deposition, thereby leading to accelerated organ damage $[30,32]$. FCGR2A on phagocytic cells is a receptor for C-reactive protein (CRP) and the serum amyloid P (SAP) component, both acting as opsonins for nuclear antigens 
$[33,34]$, and the binding between receptor and CRP or SAP might be influenced by polymorphisms [30,35], because there is a dose-response characteristic between FCGR2A-R/H131 and the risk of SLE, with an escalation of SLE risk between RR homozygotes and RH heterozygotes [30-32] . Vigato-Ferreira et al. [27] examined the allelic distribution of FCGR2A in a Brazilian population (157 SLEs and 160 controls). They found that two polymorphisms of FCGR2A were associated with SLE (FCGR2A-R-131 and RR-131), noting that the FCGR2A-H-131 allele was associated with the susceptibility to arthritis and anti-DNA antibodies [27]. In the meta-analysis performed by Li et al. [28], the FCGR2A-R/H131 variant was associated with the development of SLE in Asians both at the allele and genotype level. Low copy number of FCGR genes, including FCGR2A-RR-131, FCGR3B, and the 2B. 4 haplotype of FCGR2B, has also been reported to be associated with the susceptibility to SLE [26]. Other studies also reported the association between FCGR2A and SLE nephritis in the Korean population [36-39], demonstrating that the FCGR2A H131R missense variation is presented as a risk allele of SLE and SLE nephritis. However, the association was hard to conclude because of the lack of power due to the limited small sample size (73 to 300 patients).

In conclusion, in this study, we performed a replication study of five SNPs, previously known to be associated with SLE but not replicated in Koreans, with a relatively large amount of samples, demonstrating that rs 1801274 in FCGR2A shows a nominally significant association with SLE, but the other four SNPs appear to have no association in the Korean population. Our result is supportive that FCGR polymorphisms may play important roles in the susceptibility to SLE in diverse populations, including Koreans.

\section{Supplementary materials}

Supplementary data including one table can be found with this article online at http://www.genominfo.org/src/sm/gni14-85-s001.pdf.

\section{Acknowledgments}

This study was supported by a grant from the Korean Health Technology R\&D Project, Ministry for Health and Welfare, Republic of Korea (HI14C3417) and the National Research Foundation of Korea (NRF-2015M3C9A4053389).

\section{References}

1. Hom G, Graham RR, Modrek B, Taylor KE, Ortmann W, Garnier S, et al. Association of systemic lupus erythematosus with C8orf13-BLK and ITGAM-ITGAX. N Engl J Med 2008; 358:900-909.

2. Rhodes B, Vyse TJ. General aspects of the genetics of SLE. Autoimmunity 2007;40:550-559.

3. Cui Y, Sheng Y, Zhang X. Genetic susceptibility to SLE: recent progress from GWAS. J Autoimmun 2013;41:25-33.

4. Deng Y, Tsao BP. Genetic susceptibility to systemic lupus erythematosus in the genomic era. Nat Rev Rheumatol 2010; 6:683-692.

5. Kim JH, Jung SH, Bae JS, Lee HS, Yim SH, Park SY, et al. Deletion variants of RABGAP1L, 10q21.3, and C4 are associated with the risk of systemic lupus erythematosus in Korean women. Arthritis Rheum 2013;65:1055-1063.

6. Deapen D, Escalante A, Weinrib L, Horwitz D, Bachman B, Roy-Burman $\mathrm{P}$, et al. A revised estimate of twin concordance in systemic lupus erythematosus. Arthritis Rheum 1992;35: 311-318.

7. Kozyrev SV, Abelson AK, Wojcik J, Zaghlool A, Linga Reddy MV, Sanchez E, et al. Functional variants in the B-cell gene BANK1 are associated with systemic lupus erythematosus. Nat Genet 2008;40:211-216.

8. International Consortium for Systemic Lupus Erythematosus Genetics (SLEGEN), Harley JB, Alarcón-Riquelme ME, Criswell LA, Jacob CO, Kimberly RP, et al. Genome-wide association scan in women with systemic lupus erythematosus identifies susceptibility variants in ITGAM, PXK, KIAA1542 and other loci. Nat Genet 2008;40:204-210.

9. Han JW, Zheng HF, Cui Y, Sun LD, Ye DQ, Hu Z, et al. Genome-wide association study in a Chinese Han population identifies nine new susceptibility loci for systemic lupus erythematosus. Nat Genet 2009;41:1234-1237.

10. Graham RR, Cotsapas C, Davies L, Hackett R, Lessard CJ, Leon JM, et al. Genetic variants near TNFAIP3 on 6q23 are associated with systemic lupus erythematosus. Nat Genet 2008; 40:1059-1061.

11. Gateva V, Sandling JK, Hom G, Taylor KE, Chung SA, Sun X, et al. A large-scale replication study identifies TNIP1, PRDM1, JAZF1, UHRF1BP1 and IL10 as risk loci for systemic lupus erythematosus. Nat Genet 2009;41:1228-1233.

12. Bentham J, Morris DL, Cunninghame Graham DS, Pinder CL, Tombleson P, Behrens TW, et al. Genetic association analyses implicate aberrant regulation of innate and adaptive immunity genes in the pathogenesis of systemic lupus erythematosus. Nat Genet 2015;47:1457-1464.

13. Lessard CJ, Adrianto I, Ice JA, Wiley GB, Kelly JA, Glenn SB, et al. Identification of IRF8, TMEM39A, and IKZF3-ZPBP2 as susceptibility loci for systemic lupus erythematosus in a large-scale multiracial replication study. Am J Hum Genet 2012;90:648-660.

14. Kim HS, Kim I, Kim JO, Bae JS, Shin HD, Bae SC. No association between interleukin 23 receptor gene polymorphisms and systemic lupus erythematosus. Rheumatol Int 2009;30: 33-38.

15. Lee HS, Kim T, Bang SY, Na YJ, Kim I, Kim K, et al. Ethnic specificity of lupus-associated loci identified in a genome-wide association study in Korean women. Ann Rheum Dis 2014;73: 1240-1245.

16. Kim K, Brown EE, Choi CB, Alarcón-Riquelme ME; BIOLUPUS, Kelly JA, et al. Variation in the ICAM1-ICAM4-ICAM5 
locus is associated with systemic lupus erythematosus susceptibility in multiple ancestries. Ann Rheum Dis 2012; 71:1809-1814

17. Hochberg MC. Updating the American College of Rheumatology revised criteria for the classification of systemic lupus erythematosus. Arthritis Rheum 1997;40:1725.

18. Tan EM, Cohen AS, Fries JF, Masi AT, McShane DJ, Rothfield NF, et al. The 1982 revised criteria for the classification of systemic lupus erythematosus. Arthritis Rheum 1982;25:1271-1277.

19. 1000 Genomes Project Consortium, Abecasis GR, Auton A, Brooks LD, DePristo MA, Durbin RM, et al. An integrated map of genetic variation from 1,092 human genomes. Nature 2012;491:56-65.

20. Demirci FY, Manzi S, Ramsey-Goldman R, Minster RL, Kenney M, Shaw PS, et al. Association of a common interferon regulatory factor 5 (IRF5) variant with increased risk of systemic lupus erythematosus (SLE). Ann Hum Genet 2007;71 (Pt 3):308-311.

21. Wandstrat A, Wakeland E. The genetics of complex autoimmune diseases: non-MHC susceptibility genes. Nat Immunol 2001;2:802-809.

22. Lessard CJ, Sajuthi S, Zhao J, Kim K, Ice JA, Li H, et al. Identification of a systemic lupus erythematosus risk locus spanning ATG16L2, FCHSD2, and P2RY2 in Koreans. Arthritis Rheumatol 2016;68:1197-1209.

23. Brown EE, Edberg JC, Kimberly RP. Fc receptor genes and the systemic lupus erythematosus diathesis. Autoimmunity 2007; 40:567-581.

24. Chu ZT, Tsuchiya N, Kyogoku C, Ohashi J, Qian YP, Xu SB, et al. Association of Fcgamma receptor IIb polymorphism with susceptibility to systemic lupus erythematosus in Chinese: a common susceptibility gene in the Asian populations. Tissue Antigens 2004;63:21-27.

25. Zhou XJ, Lv JC, Qin LX, Yang HZ, Yu F, Zhao MH, et al. Is FCGR2A a susceptibility gene to systemic lupus erythematosus in Chinese? Lupus 2011;20:1198-1202.

26. Tsang-A-Sjoe MW, Nagelkerke SQ, Bultink IE, Geissler J, Tanck MW, Tacke CE, et al. Fc-gamma receptor polymorphisms differentially influence susceptibility to systemic lupus erythematosus and lupus nephritis. Rheumatology (Oxford) 2016;55:939-948.

27. Vigato-Ferreira IC, Toller-Kawahisa JE, Pancoto JA, Mendes-Junior CT, Martinez EZ, Donadi EA, et al. Fc $\gamma$ RIIa and Fc $\gamma$ RIIIb polymorphisms and associations with clinical manifestations in systemic lupus erythematosus patients. Autoimmunity 2014;47:451-458.
28. Li R, Peng H, Chen GM, Feng CC, Zhang YJ, Wen PF, et al. Association of FCGR2A-R/H131 polymorphism with susceptibility to systemic lupus erythematosus among Asian population: a meta-analysis of 20 studies. Arch Dermatol Res 2014;306:781-791.

29. Zhong H, Li XL, Li M, Hao LX, Chen RW, Xiang K, et al. Replicated associations of TNFAIP3, TNIP1 and ETS1 with systemic lupus erythematosus in a southwestern Chinese population. Arthritis Res Ther 2011;13:R186.

30. Karassa FB, Trikalinos TA, Ioannidis JP; FcgammaRIIa-SLE Meta-Analysis Investigators. Role of the Fcgamma receptor IIa polymorphism in susceptibility to systemic lupus erythematosus and lupus nephritis: a meta-analysis. Arthritis Rheum 2002;46:1563-1571.

31. Karassa FB, Trikalinos TA, Ioannidis JP. The role of FcgammaRIIA and IIIA polymorphisms in autoimmune diseases. Biomed Pharmacother 2004;58:286-291.

32. Salmon JE, Millard S, Schachter LA, Arnett FC, Ginzler EM, Gourley MF, et al. Fc gamma RIIA alleles are heritable risk factors for lupus nephritis in African Americans. J Clin Invest 1996;97:1348-1354.

33. Bharadwaj D, Stein MP, Volzer M, Mold C, Du Clos TW. The major receptor for C-reactive protein on leukocytes is fcgamma receptor II. J Exp Med 1999;190:585-590.

34. Bharadwaj D, Mold C, Markham E, Du Clos TW. Serum amyloid $\mathrm{P}$ component binds to $\mathrm{Fc}$ gamma receptors and opsonizes particles for phagocytosis. J Immunol 2001;166:6735-6741.

35. Stein MP, Edberg JC, Kimberly RP, Mangan EK, Bharadwaj D, Mold C, et al. C-reactive protein binding to FcgammaRIIa on human monocytes and neutrophils is allele-specific. J Clin Invest 2000;105:369-376.

36. Lee HS, Chung YH, Kim TG, Kim TH, Jun JB, Jung S, et al. Independent association of HLA-DR and FCgamma receptor polymorphisms in Korean patients with systemic lupus erythematosus. Rheumatology (Oxford) 2003;42:1501-1507.

37. Yun HR, Koh HK, Kim SS, Chung WT, Kim DW, Hong KP, et al. FcgammaRIIa/IIIa polymorphism and its association with clinical manifestations in Korean lupus patients. Lupus 2001; 10:466-472.

38. Kim I, Kim YJ, Kim K, Kang C, Choi CB, Sung YK, et al. Genetic studies of systemic lupus erythematosus in Asia: where are we now? Genes Immun 2009;10:421-432.

39. Song YW, Han CW, Kang SW, Baek HJ, Lee EB, Shin CH, et al. Abnormal distribution of Fc gamma receptor type IIa polymorphisms in Korean patients with systemic lupus erythematosus. Arthritis Rheum 1998;41:421-426. 